\title{
Impact of compulsory detention under the Mental Health Act 1983 on future visa and insurance applications
}

\author{
Rebecca Hurrell, ${ }^{1}$ Ben J. Di Mambro, ${ }^{2}$ Gillian A. Doody ${ }^{1}$
}

The Psychiatrist (2011), 35, 5-8, doi: 10.1192/pb.bp.110.029819

${ }^{1}$ University of Nottingham; ${ }^{2}$ Queen's Medical Centre, Nottingham

Correspondence to Rebecca Hurrell (mzyarh@nottingham.ac.uk)

\begin{abstract}
Aims and method To assess the extent to which psychiatric history, with specific regard to compulsory psychiatric admission, is questioned in visa, insurance and permit applications. Application forms for the top UK destinations for immigration, work and travel visas, six types of insurance, and driving, sporting and vocational permits were analysed.
\end{abstract}

Results Psychiatric history is questioned in some applications across all visa types. Hospital admission, but not compulsory psychiatric admission, is questioned in some immigration visas. Psychiatric history is not questioned in mortgage protection, car or pet insurance but it is questioned in some travel, life and health insurance applications, as is hospital admission. The majority of permit applications questioned psychiatric history and one vocational permit considered compulsory psychiatric admission.

Clinical implications The majority of visa, insurance and permit application forms enquire about past medical and psychiatric history. Information concerning detention under the Mental Health Act is very rarely questioned, indicating that a direct link between detention and access restriction is not evident.

Declaration of interest None.
Despite efforts to raise awareness of mental health and to address associated stigma, people with psychiatric illness remain among the most discriminated against groups in society. ${ }^{1,2}$ The Mental Health Act is utilised in situations where an individual with a psychiatric disorder poses a risk to themselves or to those around them. Yet the application of the Act in the interests of the patient may also have unintended consequences. Clinicians should be aware of any potential longer-term impact for their patient when detention is being considered. Potential restrictions to future access to financial services ${ }^{3}$ and discrimination in obtaining a visa, ${ }^{4}$ particularly to the USA, ${ }^{5}$ have already been described. With nearly 50000 people per year being subject to the Mental Health Act, ${ }^{6}$ the application of the Act may unintentionally adversely affect the lives of a significant minority of the population.

This study aims to establish the extent to which licensing authorities, visa-issuing bodies and insurers gather data about an applicant's mental health and the impact that information may subsequently have on an individual who has been detained under the Mental Health Act.

\section{Method}

An exploratory cross-sectional study was undertaken examining the relevance of compulsory detention under the
Mental Health Act, and an obligation to declare this, with respect to visa and permit applications and insurance forms.

\section{Visa applications}

A systematic sample of visa application forms for immigration, work and travel was obtained. Visa application and medical forms were downloaded from the internet, requested by email, fax or telephone from the appropriate embassy office, or obtained when meeting embassy officials and explaining the nature of the study. The top ten most popular immigration destinations for UK citizens (Australia, Spain, France, New Zealand, USA, Canada, Germany, The Netherlands, Hong Kong, United Arab Emirates (UAE)), ${ }^{7}$ plus the member countries of the Group of Eight (Canada, France, Germany, Italy, Japan, Russia, UK, USA) and the Group of Five (Brazil, China, India, Mexico, South Aftica) were listed as representative of the world's top industrialised nations. Emigration and holiday work visas or, if unavailable, temporary work visas were collected for these countries. The top 49 most frequently visited holiday destinations for British citizens ${ }^{8}$ were listed and any necessary visa applications for holidays collected. 


\section{Insurance applications}

Insurance applications and policy documents were obtained from the internet, by email and fax, or by telephone call to the relevant insurance department. The following types of insurance were considered: travel, life, car, mortgage protection, health, pet (cat and dog). A leading UK price comparison website (www.moneysupermarket.com) was accessed to obtain information on the cheapest insurance policies, which reflected the actions of the general population and minimised the potential bias caused by using only one internet website.

In the event that two or more insurance policies were underwritten by the same company, the more expensive policy was removed from the data-set. Data were entered into SPSS version 15.0 for Windows. Categorical data were analysed using cross-tabulations; qualitative data were analysed thematically.

\section{Results}

A summary of the key results is given in Tables 1 and 2 .

\section{Visas}

Visa applications and information documents were collected for 92 countries (immigration - 30, travel - 49 and work - 13).

\section{Immigration visas}

Three different immigration application forms were collected for ten countries. The immigration pathways considered were those of a skilled worker, an applicant with a family member in the country of application, and an individual with no certificated skills. Of these ten countries, four are EU members (Spain, France, Germany and The Netherlands) and therefore require no visa. The remaining six countries required visas: Australia, New Zealand, the USA, Canada, Hong Kong, and the UAE. With regard to enquiring about health, the visa applications for Hong Kong and the UAE required no information. The remaining four immigration applications (Australia, Canada, New Zealand and the USA) all requested a full medical examination as well as a complete life medical history, and specifically questioned psychiatric history. These four countries also requested information regarding the applicant's history of prescribed medication, whether hospital, medical or special care may be required in the foreseeable future and requested details of particular psychiatric disorders such as depression. Although none of the applications enquired about compulsory hospital admission, all four enquiring about medical history also questioned generic hospital admission. Australia asked whether the applicant had ever been admitted specifically for psychiatric reasons or had been referred to a mental health professional. The four countries all stated that people with conditions that may require home or institutional supervision or care, or lead to increased public expenditure, would be less likely to have a successful application. Canada and the USA also named particular psychiatric disorders which would reduce the chances of an application being successful, including any psychiatric illness associated with harmful behaviour, and antisocial, paranoid and borderline personality disorders.

\section{Work visas}

Work visa applications were considered for 19 countries. The six EU countries (France, Germany, Italy, The Netherlands, Spain and the UK) do not require work visas but the remaining 13 countries do require visas both for holiday work (Australia, Canada, Hong Kong, Japan, New Zealand) and for temporary work (Brazil, China, India, Mexico, Russia, South Africa, the UAE and the USA). Seven countries required no information on past medical history

\begin{tabular}{|c|c|c|c|c|c|c|}
\hline & \multicolumn{5}{|c|}{ Number of applications (\%) } & \multirow{2}{*}{$\begin{array}{c}\text { Stated reduced chance } \\
\text { of successful application } \\
\text { because of psychiatric } \\
\text { history, } n(\%)\end{array}$} \\
\hline & $\begin{array}{l}\text { Application } \\
\text { required }\end{array}$ & $\begin{array}{l}\text { Past medical } \\
\text { history }\end{array}$ & $\begin{array}{c}\text { Past psychiatric } \\
\text { history }\end{array}$ & $\begin{array}{c}\text { Psychiatric } \\
\text { hospital admission }\end{array}$ & $\begin{array}{c}\text { Detention } \\
\text { under MHA }\end{array}$ & \\
\hline Immigration & $6(60)$ & $4(40)$ & $4(40)$ & $1(10)$ & 0 & $4(40)$ \\
\hline Travel & $8(16)$ & $2(4)$ & $1(2)$ & 0 & 0 & 0 \\
\hline Work & $13(68)$ & 7 (37) & $5(26)$ & 0 & 0 & $3(16)$ \\
\hline
\end{tabular}

MHA, Mental Health Act.

a. The number of countries in each category was 10 for immigration visa, 49 for travel visa and 19 for work visa.

Table 2 The impact of psychiatric illness on future insurance applications for UK psychiatric patients

\begin{tabular}{|c|c|c|c|c|c|c|}
\hline & \multicolumn{5}{|c|}{ Number of applications (\%) } & \multirow{2}{*}{$\begin{array}{l}\text { Insurance that would not } \\
\text { cover claims relating to } \\
\text { pre-existing psychiatric } \\
\text { conditions, } n(\%)\end{array}$} \\
\hline & $n$ & $\begin{array}{l}\text { Past medical } \\
\text { history }\end{array}$ & $\begin{array}{c}\text { Past psychiatric } \\
\text { history }\end{array}$ & $\begin{array}{c}\text { Psychiatric } \\
\text { hospital admission }\end{array}$ & $\begin{array}{l}\text { Detention under } \\
\text { MHA }\end{array}$ & \\
\hline Travel & 8 & $8(100)$ & $2(25)$ & $1(13)$ & $1(13)$ & $8(100)$ \\
\hline Life & 6 & $6(100)$ & $6(100)$ & $1(17)$ & 0 & 0 \\
\hline Car & 10 & $10(100)$ & 0 & 0 & 0 & 0 \\
\hline Mortgage protection & 9 & $9(100)$ & 0 & 0 & 0 & $9(100)$ \\
\hline Health & 9 & $3(33)$ & $3(33)$ & $2(22)$ & 0 & $9(100)$ \\
\hline Pet & 9 & 0 & 0 & 0 & 0 & $9(100)$ \\
\hline
\end{tabular}

MHA, Mental Health Act. 
(Brazil, Hong Kong, India, Japan, Mexico, Russia and the UAE), but the remaining six work visa applications included health-related questions. Australia, South Africa and the USA required information from the applicant's complete medical life history, with all three specifically questioning psychiatric history. South Africa also required a full medical examination. Canada and China questioned the applicant's current health including psychiatric history. New Zealand enquired about the applicant's health in the 2 years before their application, but the application did not question psychiatric health specifically. No work visa application questioned medical treatment received, referral to specific medical services, or the applicant's history of hospital attendance. However, Australia, Canada and New Zealand all questioned whether hospital, special or medical care may be required during the proposed stay. Both New Zealand and the USA stated that people with medical conditions which may require home or institutional supervision or care, or lead to increased public expenditure, would reduce the likelihood of a successful application. The USA also stated particular psychiatric disorders that reduce the likelihood of a successful application.

\section{Travel visas for holidays}

Of the 49 countries considered, 8 required a visa or visa equivalent (Australia, Egypt, India, Mexico, Pakistan, Turkey, the UAE and the USA). Only Australia and the USA questioned past medical history. With regard to psychiatric history, Australia required details of all psychiatric illnesses that may incur medical costs or require medical treatment during the proposed visit. The USA questioned whether the applicant had any psychiatric disorder. No applications questioned hospital admission of any kind.

\section{Insurance}

\section{Travel insurance}

All eight travel insurance applications required the applicant to acknowledge that no pre-existing medical conditions would be covered. Furthermore, three questioned aspects of the applicant's complete life medical history and two questioned medical history 12 months prior to the application. Two applications questioned psychiatric history specifically, one enquiring about the applicant's lifetime history and the other about the preceding 12 months. Two applications questioned psychiatric treatment, yet no other type of medical treatment was questioned. One application asked specifically about depression and anxiety. Three applications asked whether the applicant had been referred to any medical specialist. No applications specifically questioned referral to a mental health professional. Only one application questioned generic hospital admission, psychiatric hospital admission and compulsory psychiatric admission. Two applications questioned whether the applicant believed that medical, hospital or special care may be required while travelling. All eight insurance companies stated that mental illness was not grounds for refusal of travel insurance. Three policies covered claims for in-patient psychiatric care provided the claimant was admitted to hospital and the illness was not pre-existing. Only one policy would cover the treatment of psychiatric illnesses that were not pre-existing and did not require admission. Of the remaining five policies, none would increase the cover to pay for claims resulting from psychiatric disorder.

\section{Life insurance}

Unsurprisingly, the six life insurance applications questioned an applicant's lifetime medical history. All applications questioned psychiatric history specifically, five enquiring about the applicant's lifetime and one about the past 5 years' history only. Five applications requested the contact details of the applicant's doctor, with four specifically stating information would be sought about their mental health. As well as questioning psychiatric history, all six applications also questioned other medical problems. Of the six life insurance applications, five asked the applicant to reveal whether they had particular psychiatric disorders. Three applications questioned referral to any medical specialist, and these three plus one other also questioned referral to a psychiatrist specifically. All six forms questioned the applicant's history of generic medical treatment ranging from current to lifelong. Two applications specifically questioned psychiatric treatment. Five applications questioned generic hospital admission, however, they were interested in varying time periods: two enquired about the applicant's complete life history, two from the past 5 years and one from the past year. One application questioned whether the applicant had ever been admitted for specific psychiatric conditions; however, none enquired about compulsory psychiatric admission. All six life insurance policies stated that psychiatric illness alone was not grounds for refusal. However, no policy covered claims arising from suicide or any pre-existing medical condition unless stated in the insurance certificate.

\section{Car insurance}

Of the ten car insurance policies obtained, seven asked the applicant to confirm that the Driver and Vehicle Licensing Agency (DVLA) was aware of any relevant medical disorder. None of the policies specifically questioned psychiatric history or hospital admission of any kind. All policies stated that if the DVLA had certified the applicant as medically fit to drive, cover would not be denied on medical grounds. However, all stated that cover would not be given to claims caused by attempted suicide or while the applicant was driving against the advice of a medical practitioner.

\section{Mortgage protection insurance}

All nine mortgage protection policies questioned whether the applicant was aware of any impending disability. Furthermore, six applications also required more in-depth health information ranging from the past year to lifetime. No applications questioned psychiatric history specifically. Two applications questioned whether the applicant had been referred to any medical specialist and three questioned the applicant's history of prescribed medication. No applications questioned psychiatric treatment specifically or hospital admission of any kind. No policies covered or requested any information about pre-existing medical conditions, and there were no possibilities to increase the coverage to include any. All policies stated psychiatric illness was not grounds for refusal and all would cover 
claims relating to a new psychiatric condition, if admitted as an in-patient.

Pet (cat and dog) insurance

Of the nine pet insurance policies screened, none questioned the applicant's medical history. No policies would cover boarding costs of a pet if the owner was admitted to hospital owing to any pre-existing medical condition. However, all policies would cover costs, up to the limit stated in the insurance certificate, if hospital admission was caused by a new psychiatric condition.

\section{Private health insurance}

Of the nine health insurance policies screened, three specifically questioned psychiatric history as well as other medical conditions. Two required information from the past 5 years and one required lifetime information. Two applications requested the contact details of the applicant's doctor. Of those three forms requesting information about psychiatric history, two enquired about particular psychiatric disorders, including depression, schizophrenia, anxiety, eating disorders and attention-deficit hyperactivity disorder. Psychiatric treatment and generic hospital admission were also enquired about in two applications along with the treatment of other medical conditions. Compulsory hospital admission was not questioned in any of the private health insurance application forms. All policies stated that psychiatric illness alone was not grounds for refusal of insurance. However, no policies covered any pre-existing medical conditions, in-patient psychiatric costs or psychiatric treatment. Four policies did not cover any ongoing costs after the initial diagnosis of any medical condition and only three covered the diagnoses of suspected psychiatric conditions. However, four policies did give an option to increase the policy to include coverage of some psychiatric care (if overseen by a consultant).

\section{Discussion}

There exists a dearth of peer-reviewed literature on the relationship between the Mental Health Act and visa or insurance applications, yet there exists much anecdotal evidence. Contrary to our expectations, it is extremely unlikely that people will be asked whether they have been compulsorily detained in an initial application. This suggests that if the Mental Health Act is taken into consideration for an application, this is carried out through subsequent enquiries into the medical history or through medical examinations/general practitioner (GP) reports.

Insurance policies do not cover pre-existing illnesses, hence any marker of the severity of the illness or the risks associated with a previous disorder is irrelevant.

Concerning visa applications, several countries stipulated in the application documentation that a history of mental illness makes a successful application less likely, yet none enquired about a history of detention under the Mental Health Act. Thus, if people with a past psychiatric history face discrimination it appears that the nature of the illness is more significant than a history of compulsory detention. With regard to permit applications, including shotgun licences, the majority enquired about medical as well as psychiatric history, along with requesting the applicant's doctor's contact details.
To minimise any potential discrimination further exploration of the visa and insurance application processes is required. Possible future research would include a combined project with insurance companies and embassies to complete and submit application forms and therefore achieve definitive answers as to the impact of psychiatric illness on an application. Specifically, this would look into how further information is gathered and interpreted by the institutions following the initial application. For example, deciding whether a GP or psychiatrist is best placed to interpret a discharge summary from a 2-day admission on a psychiatric ward where the patient was placed on a 72-hour detention order.

In conclusion, a history of detention under the Mental Health Act is very rarely enquired about when applications are made for visa or insurance. However, it remains a possibility that this information is obtained subsequent to the initial application if an initial screen results in a positive answer.

So what should a psychiatrist tell a patient who asks whether compulsory detention will have any detrimental effect on their future travel plans or insurance policies? Currently, the only country that asks specifically about detention for visa purposes is the USA. A previously detained patient should allow extra time to obtain a travel visa and some people may be declined a visa, dependent on further enquiry. Insurers do not enquire about compulsory detention, but as with illness, pre-existing conditions are not covered.

\section{About the authors}

Rebecca Hurrell, Medical Student, University of Nottingham, Ben J. Di Mambro, Consultant Perinatal Psychiatrist and Clinical Teaching Fellow, Queen's Medical Centre, Nottingham, Gillian A. Doody, Clinical Associate Professor in General Adult Psychaitry, University of Nottingham, Division of Psychiatry.

\section{References}

1 Stuart H. Fighting the stigma caused by mental disorders: past perspectives, present activities, and future directions. World Psychiatry 2008; 7: 185-8.

2 Thornicroft G, Brohan E, Kassam A, Lewis-Holmes E. Reducing stigma and discrimination: candidate interventions. Int $J$ Ment Health Syst 2008; 2 : 3.

3 Henderson C, Flood C, Leese M, Thornicroft G, Sutherby K, Szmukler G. Effect of joint crisis plans on use of compulsory treatment in psychiatry: single-blind randomised controlled trial. BMJ 2004; 329: 745-8.

4 Allen D, Allen K. Do patients who have been on 'sections' get refused visas? Psychiatr Bull 1994; 18: 216-7.

5 Duggirala C. Refusal of visas. Psychiatr Bull 1994; 18: 508.

6 Department of Health. In-Patients Formally Detained in Hospitals under the Mental Health Act 1983 and Other Legislation, England: 1996-97 to 2006-07. Government Statistical Service, 2007.

7 Office for National Statistics. International Migration, Series MN No. 33 ONS, 2006 (http://www.statistics.gov.uk/StatBase/Product. asp?vink=507).

8 Office for National Statistics. Travel Trends 2006 - A Report on the International Passenger Survey. ONS, 2008 (http://www.statistics.gov.uk/ downloads/theme_transport/TravelTrends2006.pdf). 